\title{
Effect of Neonatal Intensive Care Unit Hospitalization on Incidence of Attention Deficit Hyperactivity Disorder in Preschool Children
}

\author{
Marjan Teimourzadeh Baboli, ${ }^{1}$ Yadollah Zahed Pasha, ${ }^{2}$ Seyedeh Shokoufeh Mousavi, ${ }^{3}$ Soraya Khafri, \\ and Mohsen Haghshenas ${ }^{2, *}$ \\ ${ }^{1}$ Department of Nursing, School of Medicine, Babol University of Medical Sciences, Babol, IR Iran \\ ${ }^{2}$ Department of Pediatrics, School of Medicine, Babol University of Medical Sciences, Babol, IR Iran \\ ${ }^{3}$ Department of Psychiatry and Neurology, Babol University of Medical Sciences, Babol, IR Iran \\ ${ }^{4}$ Department of Social Medicine and Health, Babol University of Medical Sciences, Babol, IR Iran \\ "Corresponding author: Mohsen Haghshenas, Non-Communicable Pediatric Diseases Research Center, Amirkola Children's Hospital, Babol, IR Iran. Tel: +98-1132354951, Fax: \\ +98-1132346963, E-mail: matia.mojaveri@yahoo.com
}

Received 2015 June 19; Revised 2015 December 12; Accepted 2016 January 15.

\begin{abstract}
Background: The exact etiology of attention deficit hyperactivity disorder (ADHD) has not yet been understood.

Objectives: The aim of the current study was to investigate the effects of hospitalization at the neonatal intensive care unit (NICU) independent of other variables such as preterm birth and low birth weight on the incidence of ADHD.

Materials and Method: This retrospective cohort study was done on an Exposed group of 100 preschool children with a history of NICU hospitalization at Amirkola children's hospital, and an unexposed group of 100 children without such a history. Standard checklist of Diagnostic and statistic manual of mental disorders fourth edition (DSM-IV) was used to diagnose ADHD. Information on gender, current weight, birth weight, gestational age at birth, and type of parturition was also collected and obtained data were statistically analyzed by the SPSS software and unconditional logistic regression analysis.

Results: Among the total number of 200 children, $20.5 \%$ of children were diagnosed to have ADHD. The incidence of the disorder was more in children with a history of hospitalization in neonatal intensive care unit than children without such a history (27\% and $14 \%$, respectively). Low birth weight and preterm birth were associated with the incidence of ADHD ( $\mathrm{Pvalue}=0.001$ and 0.005 , respectively). Logistic regression showed that each day of NICU hospitalization was associated with 1.16 times greater risk of developing ADHD in the future when compared to children without a history of hospitalization (P value $=0.006$ ).

Conclusions: The risk of ADHD is independently increased with hospitalization at the NICU.
\end{abstract}

Keywords: Attention Deficit Hyperactivity Disorder, Intensive Care Unit, Neonatal, Preschool Ages

\section{Background}

Every year, 14.9 million (more than 1 in 10) children are born prematurely all over the world (1). Following the advances in perinatal care, an increasing number of preterm infants reach childhood (2). Negative effects of preterm birth on neurodevelopmental and psychiatric development of children and adolescents have been well documented (3-8). Severe neurological impairment has been reported in 10 to $12 \%$ of school-aged children, who were born very preterm (less than 32 weeks of gestation) (912). Mild neurocognitive disorders such as lower IQ and poor academic achievement have been reported more frequently (4,13-18).

Attention deficit hyperactivity disorder (ADHD) is a neurobehavioral syndrome characterized by attention deficit, impulsivity and hyperactivity. It can be considered a generalized impulsivity disorder, with the traits of impulsivity manifesting at the motor, emotional, social, and attention levels (19). This disorder was described more than a century ago, as a behavioral disorder seen more often in boys. Attention deficit hyperactivity disorder is the most common neurodevelopmental disorder in Western countries (17) with a reported prevalence rate of 3 to $9 \%$ and a male to female ratio of 3:1 to 5:1 in previous studies (20-22). Investigations by the American Psychiatric Association, which were published in the Diagnostic and statistical manual of mental disorders 4th edition (DSM-IV), showed a prevalence of 3 to $5 \%$ for ADHD in adults with an equal male-female ratio (23-25).

The exact etiology of ADHD is still unknown, although many factors have been suggested as risk factors for the development of this disorder, including: preterm birth, low birth weight, genetic factors, environmental factors such as contact with toxic substances like lead, alcohol, and Poly-Chlorinated Biphenyl (PCP), inappropriate socioeconomic status, and perinatal complications such as intrauterine growth retardation and perinatal asphyxia (16, 
26-33).

Since 1961, many improvements in devices and care have taken place. Although with the invention of neonatal intensive care unit, infant mortality rates, especially among preterm and low birth weight infants have been significantly reduced, these babies face many complications. These infants are under pressure and irritation, due to their specific condition. Moreover, they are influenced by potentially harmful environmental factors such as light and sound, magnetic fields, radiation, inactive ingredients of drugs and chemical substances. Premature infants are more vulnerable compared with older children and adults due to the evolution of organ systems, and are less able to deal with the problems of life outside the uterus (34).

Several studies have reported a relationship between prematurity, low birth weight (which are the leading causes of hospitalization in NICU) and the incidence of ADHD during childhood and adolescence $(4,16,33,35,36)$. The question now is whether NICU hospitalization can increase the risk of ADHD. No study has ever investigated the relationship between NICU hospitalization and development of ADHD in the future, as an independent factor.

\section{Objectives}

The aim of the current study was to investigate the effects of hospitalization at the NICU, independent of other variables such as preterm birth and low birth weight, on the incidence of ADHD.

\section{Materials and Methods}

This study was a retrospective cohort study. Regarding the prevalence of ADHD in previous studies, the sample size needed for the study was calculated as 100 samples in the group with a history of NICU hospitalization and 100 samples in the group without a history of hospitalization.

Six to seven-year-old children with a history of neonatal intensive care unit hospitalization in Amirkola children's hospital were included in the exposed group of our study. We asked parents about the child's history of NICU hospitalization and then checked the hospital archives. Samples in the unexposed group were preschool children without a history of hospitalization, who were selected randomly among Babol's preschool centers. Exposed and unexposed groups were matched for age. Children hospitalized in the NICU because of severe congenital defects, chromosomal anomalies, maternal drug abuse, parental separation, serious injuries during birth, and intractable seizures were excluded from the study. High and low birth weight infants $(>6$ and $<3$ standard deviation from the
Marsal's growth chart) (37), who could lead to a possible coding error (38), were also excluded.

After initial sample selection, the mothers of these children were contacted and sampling was continued by obtaining informed consent to reach the sample volume calculated. Finally, our study population consisted of 200 preschool children, who were born to Iranian mothers.

To diagnose ADHD, the standard checklist of DSM-IV was used. The DSM criteria were used for clinical-medical studies, and neurological evaluations were performed for diagnosis of ADHD by a psychiatrist (39). Other information such as gender, weight, birth weight, and gestational weeks at birth, delivery type, and days hospitalized in the NICU were collected and finally all the data were entered into the statistical analysis software.

The data from the study was analyzed using SPSS v.20. First, descriptive statistics was used to summarize the data. Then, appropriate statistical tests (chi-square, t-test and Mann-Whitney) were performed to estimate the association between studied variables and ADHD incidence. Finally, to estimate the impact of NICU hospitalization on the incidence of ADHD as the outcome variable, unconditional logistic regression was used to calculate odds ratio with $95 \%$ confidence interval. Since risk ratio should be reported in cohort studies, odd ratio was converted to risk ratio $(40,41)$.

\section{Results}

Amongst a total of 200 children, 103 were boys (51.5\%) and 97 children were girls $(48.5 \%)(\mathrm{P}=0.038)$. In terms of age, $49.2 \%$ of children were six years old, and $50.8 \%$ were seven years old $(P=0.15)$.

The results showed that $33.5 \%$ of children had one of three subtypes of ADHD (ADHD-I: inattention disorder, ADHD-II: hyperactivity and impulsivity disorder, ADHD-C: combined disorder). The incidence of ADHD-C (20.5\%) was more than the two other subtypes (6.5\% and 6\% in ADHD-I and ADHD-II, respectively).

The incidence of ADHD was $27 \%$ in children with a history of NICU hospitalization and 14\% in children with no history of NICU hospitalization. Among children with a history of NICU hospitalization, $23.9 \%$ had low birth weight $(<2500$ gram $)$ and $30.8 \%$ were preterm $(<37$ gestational weeks).

Table 1, summarizes the association between study variables and ADHD in preschool children. Fischer's exact test showed that the incidence of ADHD is more frequent in boys (22\%) than girls (19\%) (P value $=0.038)$. The test also showed that there was no significant difference between six- and seven-year-old children in terms of ADHD (P value 
$=0.23)$. Also, there was no statistically significant association between delivery type and ADHD (P value $=0.55$ ).

Table 1. The Association Between Study Variables and Attention-Deficit Hyperactivity Disorder Incidence in Preschool Children Using Fischer's Exact Test

\begin{tabular}{|c|c|c|}
\hline Variable & Frequency in Children With ADHD, \% & P Value \\
\hline Age, $y$ & & 0.150 \\
\hline 6 & 38.6 & \\
\hline 7 & 30.6 & \\
\hline Gender & & 0.038 \\
\hline Boy & 22 & \\
\hline Girl & 19 & \\
\hline Delivery Type & & 0.873 \\
\hline C-section & 21 & \\
\hline Vaginal & 20 & \\
\hline Low Birth Weight & & 0.000 \\
\hline Yes & 34 & \\
\hline No & 16 & \\
\hline Preterm Birth & & 0.005 \\
\hline Yes & 31 & \\
\hline No & 16 & \\
\hline NICU Hospitalization & & 0.001 \\
\hline Yes & 27 & \\
\hline No & 14 & \\
\hline
\end{tabular}

To assess the association between gestational age and ADHD, Fischer's exact test was used and the results showed that the incidence of ADHD is significantly more frequent in premature infants (31\%) than mature infants (16\%) (P value $=0.002)$. T-test revealed a statistically significant association between gestational weeks and the incidence of ADHD $(\mathrm{P}$ value $=0.00)$. The average gestational age was $35.49 \pm 3.84$ weeks in children with ADHD and $36.78 \pm 2.31$ in children without ADHD (Table 2).

Evaluation of the association between birth weight and incidence of ADHD using T-test showed that there was no statistically significant relationship between these variables $($ Pvalue $=0.85)$. By categorizing the infants to low and normal birth weight and using Fischer's exact test, there was a significant association between low birth weight and ADHD (P value $=0.003$ ). The prevalence of ADHD was 34\% and $16 \%$ in children with low birth weight and normal birth weight, respectively. Current weight of children had no significant association with ADHD $(P$ value $=0.46)($ Table 1).

As mentioned earlier, the prevalence of ADHD in children with a history of NICU hospitalization (case group) was more than children without such a history (control group). To evaluate the association between history of NICU hospitalization and incidence of ADHD in preschool ages, Fischer's exact test was initially used. The results revealed a significant difference between the two groups ( $P$ value $=0.00)$. The average NICU hospitalization days were $6.31 \pm 5.38$ and $3.11 \pm 4.59$ days in children with and without ADHD, respectively (Figure 1). The association between days hospitalized in NICU and the incidence of ADHD was evaluated using the T-test. The results showed a statistically significant association between days hospitalized and $\operatorname{ADHD}($ P value $=0.01)($ Table 2$)$.

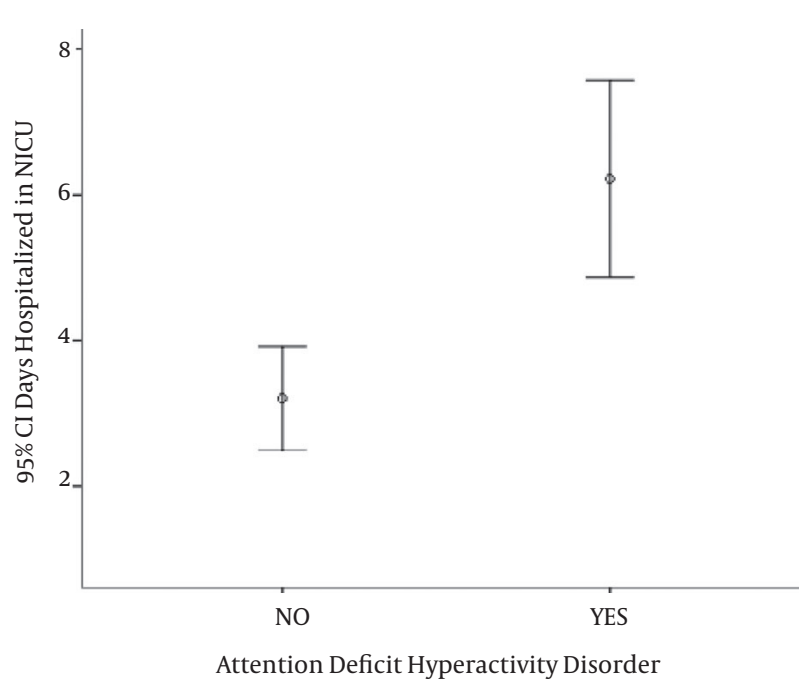

Figure 1. Ninety-Five Percent Confidence Interval of Days of Hospitalization at the Neonatal Intensive Care Unit in Terms of Developing Attention Deficit Hyperactivity Disorder During Childhood

Unconditional logistic regression (backward stepwise) was used to determine the relationship between the incidence of ADHD and NICU hospitalization (Table 3). This regression showed that the days hospitalized at the NICU and gender was associated with ADHD in preschool children.

\section{Discussion}

In this retrospective cohort study, which was performed on 200 preschool aged children, the independent relationship between NICU hospitalization and the incidence of ADHD was tested. The prevalence of ADHD among children with a history of hospitalization in NICU and children without such a history was $27 \%$ and $14 \%$, respectively. The difference between the two groups was statistically significant. Neonatal intensive care unit hospitalization makes the risk of developing ADHD in preschool ages 1.16 
Table 2. Association Between Study Variables and Attention-Deficit Hyperactivity Disorder Incidence in Preschool Children Using Independent-Samples T-Test

\begin{tabular}{lcc}
\hline Variable & \multicolumn{2}{c}{ Average and Standard Deviation Values in Children } \\
\cline { 2 - 3 } & With ADHD & Without ADHD \\
\hline Current Weight, $\mathbf{~ k g}$ & $21.8 \pm 4.4$ & $21.3 \pm 4.8$ \\
\hline Birth Weight, $\mathbf{~ k g}$ & $2.658 \pm 0.861$ & $2.937 \pm 0.684$ \\
\hline Gestational Age, $\mathbf{w}$ & $35.49 \pm 3.84$ & $36.78 \pm 2.31$ \\
\hline Days Hospitalized in NICU, $\mathbf{d}$ & $6.31 \pm 5.38$ & $3.11 \pm 4.59$ \\
\hline
\end{tabular}

Table 3. Unconditional Logistic Regression of the Incidence of Attention Deficit Hyperactivity Disorder and Neonatal Intensive Care Unit Hospitalization

\begin{tabular}{|c|c|c|c|c|}
\hline \multirow[t]{2}{*}{ Variable } & \multirow[t]{2}{*}{ Risk Ratio } & \multicolumn{2}{|c|}{ CI 95\% } & \multirow[t]{2}{*}{ P Value } \\
\hline & & Lower & Upper & \\
\hline Age ( 6 or 7$)$ & 1.26 & 0.614 & 2.428 & 0.570 \\
\hline Gender (boy or girl) & 1.16 & 0.252 & 0.919 & 0.027 \\
\hline Current Weight & 1.00 & 1.000 & 1.000 & 0.427 \\
\hline Preterm Labor & 1.94 & 0.674 & 2.904 & 0.368 \\
\hline Low Birth Weight & 1.00 & 1.000 & 1.000 & 0.719 \\
\hline History of NICU Hospitalization & 1.93 & 0.397 & 3.197 & 0.824 \\
\hline Days Hospitalized in NICU & 1.18 & 1.044 & 1.292 & 0.006 \\
\hline
\end{tabular}

times greater. Therefore, after a week's stay at NICU, the risk of ADHD at preschool ages becomes 1.93 times greater.

Several studies suggested that attention problems are more frequent among children born preterm. Farooqi et al. (33) found that eleven-year-old children born after 23 to 25 weeks of gestation develop ADHD, three to four times more than term infants (after 37 weeks of pregnancy). However, Stjernqvist and Svenningsen (16) stated a twofold increase in a study carried out on ten-year-old children, who were born before 29 weeks of gestation. A recent French study on 1102 five-year-old children born between 22 and 32 weeks of gestation showed a two-fold risk of ADHD compared to the control term group (42). Followup studies of ADHD in preterm infants are concentrated with some exceptions on children, who were born very preterm and have received care in NICUs (4), and no study has investigated the difference in the incidence of ADHD between children with a history of NICU hospitalization and those without such a history.

There are evidences of developmental delay in children with ADHD (43). The delay has also been recognized using imaging techniques. Children with ADHD reach the maximum cortical narrowness three years later than healthy controls (44). It has been hypothesized that the effects of perinatal factors become evident during the development
(45). It seems reasonable to assume that such factors are effective on development of ADHD symptoms in children, who are born preterm.

The current study is the first to report the impact of NICU hospitalization independent of factors such as preterm labor and low birth weight. A large number of infants hospitalized at the NICU are born preterm, the brain connections of whom are still not fully formed. The maximal amount of cortical connections refinement took place in weeks 24 to 28 of pregnancy. The corrected mean number of neurons reaches a maximum at 28 weeks of gestation, and estimated number of neurons is significantly higher at 28 to 32 weeks of gestation than at 17 to 20 gestational weeks and at 0 to 13 postnatal weeks $(45,46)$. As a result, infants who are admitted to the NICU are more vulnerable to environmental harmful factors affecting the neurobehavioral systems.

It can be concluded from the results of this study that NICU hospitalization increases the possibility of ADHD in the future, independently. This finding, which needs to be confirmed by further studies with greater sample sizes in a multi-central fashion and by including more mediator/confounding variables such as behavioral and socioeconomic factors related to parents, indicates the necessity of reducing possible damaging elements in the NICUs. The 
answer to the question of how neonatal intensive care unit can cause developmental damages requires comprehensive researches.

\section{Acknowledgments}

We are grateful to the clinical research development committee of Amirkola children's hospital and Faeze Aghajanpour for their contribution to this study. We appreciate the sincere cooperation of the head nurse of Amirkola children's hospital NICU, Jahangir, who provided us with the data of children, who were admitted seven years ago. We also like thank Ali Bijani for his support and sharing of valuable experiences.

\section{Footnotes}

Authors' Contribution: Marjan Teimourzadeh Baboli conceived and designed the evaluation, collected the clinical data and interpreted them, drafted the manuscript and revised it critically for important intellectual content. Yadollah Zahed Pasha and Seyedeh Shokoufeh Mousavi participated in interpretation of clinical data. Soraya Khafri participated in interpretation of clinical data, performed the statistical analysis and revised the manuscript critically for important intellectual content. Mohsen Haghshenas participated in designing the manuscript, interpretation of the clinical data and revision of the manuscript critically for important intellectual content. All authors read and approve the final manuscript.

Declaration of Interest: None declared.

Funding/Support: This study was supported by a research grant and was part of an MSC student thesis of Marjan Teimorzadeh Baboli from the non-communicable pediatric diseases research center of Babol University of Medical Sciences (Grant Number: 9237516).

\section{References}

1. Bieleninik L, Gold C. Early intervention for premature infants in neonatal intensive care unit. Acta Neuropsychologica. 2014;12(2):185203.

2. Garcia-Munoz Rodrigo F, Diez Recinos AL, Garcia-Alix Perez A, Figueras Aloy J, Vento Torres M. Changes in perinatal care and outcomes in newborns at the limit of viability in Spain: the EPI-SEN Study. Neonatology. 2015;107(2):120-9. doi:10.1159/000368881. [PubMed: 25502078]

3. Eaton WW, Mortensen PB, Thomsen PH, Frydenberg M. Obstetric complications and risk for severe psychopathology in childhood.JAutism Dev Disord. 2001;31(3):279-85. [PubMed:11518482].

4. Bhutta AT, Cleves MA, Casey PH, Cradock MM, Anand KJ. Cognitive and behavioral outcomes of school-aged children who were born preterm: a meta-analysis. JAMA. 2002;288(6):728-37. [PubMed 12169077].
5. Aarnoudse-Moens CS, Weisglas-Kuperus N, van Goudoever JB, Oosterlaan J. Meta-analysis of neurobehavioral outcomes in very preterm and/or very low birth weight children. Pediatrics. 2009;124(2):717-28. doi: 10.1542/peds.2008-2816. [PubMed: 19651588].

6. Ahlsson F, Kaijser M, Adami J, Lundgren M, Palme M. School performance after preterm birth. Epidemiology. 2015;26(1):106-11. doi: 10.1097/EDE.0000000000000171. [PubMed: 25215531].

7. Cosentino-Rocha L, Klein VC, Linhares MB. Effects of preterm birth and gender on temperament and behavior in children. Infant Behav Dev. 2014;37(3):446-56. doi: 10.1016/j.infbeh.2014.04.003. [PubMed: 24793755].

8. Rabie NZ, Bird TM, Magann EF, Hall RW, McKelvey SS. ADHD and developmental speech/language disorders in late preterm, early term and term infants.J Perinatol. 2015;35(8):660-4. doi:10.1038/jp.2015.28. [PubMed: 25836321].

9. Walther FJ, den Ouden AL, Verloove-Vanhorick SP. Looking back in time: outcome of a national cohort of very preterm infants born in The Netherlands in 1983. Early Hum Dev. 2000;59(3):175-91. [PubMed: 10996273].

10. Ornstein M, Ohlsson A, Edmonds J, Asztalos E. Neonatal followup of very low birthweight/extremely low birthweight infants to school age: a critical overview. Acta Paediatr Scand. 1991;80(8-9):7418. [PubMed: 1720269].

11. Tronnes H, Wilcox AJ, Lie RT, Markestad T, Moster D. Risk of cerebral palsy in relation to pregnancy disorders and preterm birth: a national cohort study. Dev Med Child Neurol. 2014;56(8):779-85. doi: 10.1111/dmcn.12430. [PubMed: 24621110].

12. Christian P, Murray-Kolb LE, Tielsch JM, Katz J, LeClerq SC, Khatry SK. Associations between preterm birth, small-for-gestational age, and neonatal morbidity and cognitive function among school-age children in Nepal. BMC Pediatr. 2014;14:58. doi: 10.1186/1471-2431-14-58. [PubMed: 24575933].

13. Saigal S, den Ouden L, Wolke D, Hoult L, Paneth N, Streiner DL, et al. School-age outcomes in children who were extremely low birth weight from four international population-based cohorts. Pediatrics. 2003;112(4):943-50. [PubMed: 14523190].

14. Ericson A, Kallen B. Very low birthweight boys at the age of 19. Arch Dis Child Fetal Neonatal Ed. 1998;78(3):F171-4. [PubMed: 9713026].

15. Saigal S, Hoult LA, Streiner DL, Stoskopf BL, Rosenbaum PL. School difficulties at adolescence in a regional cohort of children who were extremely low birth weight. Pediatrics. 2000;105(2):325-31. [PubMed: 10654950].

16. Stjernqvist K, Svenningsen NW. Ten-year follow-up of children born before 29 gestational weeks: health, cognitive development, behaviour and school achievement. Acta Paediatr. 1999;88(5):557-62. [PubMed: 10426181].

17. Rowland AS, Lesesne CA, Abramowitz AJ. The epidemiology of attention-deficit/hyperactivity disorder (ADHD): a public health view. Ment Retard Dev Disabil Res Rev. 2002;8(3):162-70. doi: 10.1002/mrdd.10036. [PubMed: 12216060]

18. Boardman JP, Walley A, Ball G, Takousis P, Krishnan ML, HughesCarre $\mathrm{L}$, et al. Common genetic variants and risk of brain injury after preterm birth. Pediatrics. 2014;133(6):1655-63. doi: 10.1542/peds.20133011. [PubMed: 24819575].

19. Rubia K, Smith AB, Brammer MJ, Toone B, Taylor E. Abnormal brain activation during inhibition and error detection in medication-naive adolescents with ADHD. Am J Psychiatry. 2005;162(6):1067-75. doi: 10.1176/appi.ajp.162.6.1067. [PubMed: 15930054].

20. Froehlich TE, Lanphear BP, Epstein JN, Barbaresi WJ, Katusic SK, Kahn RS. Prevalence, recognition, and treatment of attentiondeficit/hyperactivity disorder in a national sample of US children. Arch Pediatr Adolesc Med. 2007;161(9):857-64. doi: 10.1001/archpedi.161.9.857. [PubMed:17768285].

21. Skounti M, Philalithis A, Galanakis E. Variations in prevalence of attention deficit hyperactivity disorder worldwide. Eur J Pediatr. 2007;166(2):117-23. doi: 10.1007/s00431-006-0299-5. [PubMed: 17033803]. 
22. Shear K, Jin R, Ruscio AM, Walters EE, Kessler RC. Prevalence and correlates of estimated DSM-IV child and adult separation anxiety disorder in the National Comorbidity Survey Replication. Am J Psychiatry. 2006;163(6):1074-83. doi: 10.1176/ajp.2006.163.6.1074. [PubMed: 16741209].

23. Faraone SV, Sergeant J, Gillberg C, Biederman J. The worldwide prevalence of ADHD: is it an American condition?. World Psychiatry. 2003;2(2):104-13. [PubMed: 16946911].

24. Kessler RC, Adler L, Barkley R, Biederman J, Conners CK, Demler O, et al. The prevalence and correlates of adult ADHD in the United States: results from the National Comorbidity Survey Replication. Am J Psychiatry. 2006;163(4):716-23. doi: 10.1176/ajp.2006.163.4.716. [PubMed: 16585449].

25. Wilens TE, Spencer TJ, Biederman J. A review of the pharmacotherapy of adults with attention-deficit/hyperactivity disorder.J Atten Disord. 2002;5(4):189-202. [PubMed: 11967475].

26. Millichap JG. Etiologic classification of attentiondeficit/hyperactivity disorder. Pediatrics. 2008;121(2):358-65. doi: 10.1542/peds.2007-1332. [PubMed: 18245408].

27. Banerjee TD, Middleton F, Faraone SV. Environmental risk factors for attention-deficit hyperactivity disorder. Acta Paediatr. 2007;96(9):1269-74. doi: 10.1111/j.1651-2227.2007.00430.x. [PubMed: 17718779].

28. Famularo R, Kinscherff R, Fenton T. Psychiatric diagnoses of maltreated children: preliminary findings. J Am Acad Child Adolesc Psychiatry. 1992;31(5):863-7. doi: 10.1097/00004583-199209000-00013. [PubMed: 1400118].

29. Biederman J, Milberger S, Faraone SV, Kiely K, Guite J, Mick E, et al. Family-environment risk factors for attention-deficit hyperactivity disorder. A test of Rutter's indicators of adversity. Arch Gen Psychiatry. 1995;52(6):464-70. [PubMed: 7771916].

30. Hjern A, Weitoft GR, Lindblad F. Social adversity predicts ADHD medication in school children-a national cohort study. Acta Paediatr. 2010;99(6):920-4. doi: 10.1111/j.1651-2227.2009.01638.x. [PubMed: 20002622]

31. Strang-Karlsson S, Raikkonen K, Pesonen AK, Kajantie E, Paavonen EJ, Lahti J, et al. Very low birth weight and behavioral symptoms of attention deficit hyperactivity disorder in young adulthood: the Helsinki study of very-low-birth-weight adults. Am J Psychiatry. 2008;165(10):1345-53. doi: 10.1176/appi.ajp.2008.08010085. [PubMed: 18628349].

32. O'Keeffe MJ, O'Callaghan M, Williams GM, Najman JM, Bor W. Learning, cognitive, and attentional problems in adolescents born small for gestational age. Pediatrics. 2003;112(2):301-7. [PubMed: 12897278].

33. Farooqi A, Hagglof B, Sedin G, Gothefors L, Serenius F. Mental health and social competencies of 10- to 12-year-old children born at 23 to 25 weeks of gestation in the 1990s: a Swedish national prospective follow-up study. Pediatrics. 2007;120(1):118-33. doi: 10.1542/peds.2006-
2988. [PubMed: 17606569].

34. Lai TT, Bearer CF. Iatrogenic environmental hazards in the neonatal intensive care unit. Clin Perinatol. 2008;35(1):163-81. doi: 10.1016/j.clp.2007.11.003. [PubMed: 18280881] ix.

35. Lindstrom K, Lindblad F, Hjern A. Preterm birth and attentiondeficit/hyperactivity disorder in schoolchildren. Pediatrics 2011;127(5):858-65. doi: 10.1542/peds.2010-1279. [PubMed: 21502231].

36. Breslau N, Brown GG, DelDotto JE, Kumar S, Ezhuthachan S, Andreski $P$, et al. Psychiatric sequelae of low birth weight at 6 years of age. $J A b$ norm Child Psychol. 1996;24(3):385-400. [PubMed: 8836807].

37. Haglund B. Birthweight distributions by gestational age: comparison of LMP-based and ultrasound-based estimates of gestational age using data from the Swedish Birth Registry. Paediatr Perinat Epidemiol. 2007;21 Suppl 2:72-8. doi: 10.1111/j.1365-3016.2007.00863.x. [PubMed: 17803620].

38. Delobel-Ayoub M, Arnaud C, White-Koning M, Casper C, Pierrat V Garel M, et al. Behavioral problems and cognitive performance at 5 years of age after very preterm birth: the EPIPAGE Study. Pediatrics. 2009;123(6):1485-92. doi:10.1542/peds.2008-1216. [PubMed:19482758].

39. Pineda DA, Puerta IC, Aguirre DC, Garcia-Barrera MA, Kamphaus RW. The role of neuropsychologic tests in the diagnosis of attention deficit hyperactivity disorder. Pediatr Neurol. 2007;36(6):373-81. doi: 10.1016/j.pediatrneurol.2007.02.002. [PubMed: 17560498].

40. Wang Z. Converting odds ratio to relative risk in cohort studies with partial data information. J Stat Softw. 2013;55(5):1-11.

41. Samet JM, Munoz A. Evolution of the cohort study. Epidemiol Rev. 1998;20(1):1-14. [PubMed: 9762505].

42. Mann C, Lubar JF, Zimmerman AW, Miller C, Muenchen RA. Quantitative analysis of EEG in boys with attention-deficit-hyperactivity disorder: Controlled study with clinical implications. Pediatr Neurol. 1992;8(1):30-6.

43. Shaw P, Eckstrand K, Sharp W, Blumenthal J, Lerch JP, Greenstein D, et al. Attention-deficit/hyperactivity disorder is characterized by a delay in cortical maturation. Proc Natl Acad SciUSA. 2007;104(49):19649-54. doi: 10.1073/pnas.0707741104. [PubMed:18024590].

44. Makris N, Biederman J, Monuteaux MC, Seidman LJ. Towards conceptualizing a neural systems-based anatomy of attentiondeficit/hyperactivity disorder. Dev Neurosci. 2009;31(1-2):36-49. doi: 10.1159/000207492. [PubMed: 19372685].

45. Marsh R, Gerber AJ, Peterson BS. Neuroimaging studies of normal brain development and their relevance for understanding childhood neuropsychiatric disorders. J Am Acad Child Adolesc Psychiatry. 2008;47(11):1233-51. doi: 10.1097/CHI.0b013e318185e703. [PubMed 18833009].

46. Rabinowicz T, de Courten-Myers GM, Petetot JM, Xi G, de los Reyes E. Human cortex development: estimates of neuronal numbers indicate major loss late during gestation. J Neuropathol Exp Neurol. 1996;55(3):320-8. [PubMed: 8786390]. 